\title{
IMPACTOS SOCIAIS DOS NOVOS FLUXOS MIGRATÓRIOS E POLÍTICAS LINGUÍSTICAS NO BRASIL: O ENSINO DE PORTUGUÊS COMO LÍNGUA DE ACOLHIMENTO (PLAc)
}

\author{
IMPACTOS SOCIALES DE LOS NUEVOS FLUJOS MIGRATORIOS Y POLIITICAS \\ LINGÜÍSTICAS EN BRASIL: LA ENSEÑANZA DE PORTUGUÉS COMO LENGUA DE \\ ACOGIMIENTO (PLAC)
}

\section{SOCIAL IMPACTS OF NEW MIGRATORY FLOWS AND LANGUAGE POLICIES IN BRAZIL: THE TEACHING OF PORTUGUESE AS A WELCOMING LANGUAGE}

\author{
Mariana BULEGON ${ }^{1}$ \\ Laura Fontana SOARES ${ }^{2}$
}

RESUMO: Neste trabalho, consideramos o ensino de Português como Língua de Acolhimento (PLAc) no Brasil como uma maneira de produzir agenciamento em prol da conquista de direitos aos imigrantes deslocados forçados. Nossa motivação para empreender esta discussão se dá uma vez que o ensino de PLAc é recentemente debatido nas esferas públicas e acadêmicas, consequentemente, são necessárias pesquisas que se somem à temática, à luz das políticas linguísticas que se constroem nas horizontalidades e nas verticalidades, em camadas que se sobrepõem. Para mais, ao longo de nossas pesquisas, nos deparamos com a falta de materiais teóricos e didáticos - para professores e alunos - que tratem do ensino de PLAc sob a perspectiva da reterritorialização e agentividade. Como elaborar um ensino acolhedor, de fato, sem reproduzir modelos que excluem, que separam o aluno imigrante do(a) professor(a) brasileiro(a)? O PLAc se configura como ensino de língua diminuitivo ou aditivo ao passo que é a língua de um novo espaço de vivências para sujeitos migrantes? Tendo em vista o estado da arte das pesquisas e asserções, até o momento, e as propostas sobre o acolhimento em língua portuguesa, buscamos refletir de que forma o PLAc incide sobre as políticas para imigrantes refugiados no Brasil, além de discutirmos as nomenclaturas imigrante e refugiado.

PALAVRAS-CHAVE: Português como Língua de Acolhimento. Deslocados forçados. Políticas linguísticas. Políticas sociais.

RESUMEN: En este trabajo, consideramos la enseñanza de Portugués como Lengua de Acogimiento (PLAc) en Brasil como un modo de producir agencia en favor de la conquista de derechos iguales a los inmigrantes dislocados forzados. Nuestra motivación para efectuar esta discusión ocurre en razón de que la enseñanza de PLAc ha sido recientemente debatida en las esferas públicas y académicas, consecuentemente, investigaciones que se sumen al tema son necesarias, a la luz de las políticas lingüísticas que se construyen en las horizontalidades y en las verticalidades, en camadas que se sobreponen. Además, a lo largo de nuestras

1 Universidade Federal do Rio Grande do Sul (UFRGS), Porto Alegre - RS - Brasil. Mestranda em Linguística Aplicada. Bolsista CAPES. ORCID: <http://orcid.org/0000-0002-1064-1691>. E-mail: bulegonm@gmail.com ${ }^{2}$ Universidade Federal do Rio Grande do Sul (UFRGS), Porto Alegre - RS - Brasil. Mestranda em Linguística Aplicada. Bolsista CNPq. ORCID: <http://https://orcid.org/0000-0001-6100-4556>. E-mail: 1.fontanasoares@gmail.com 
investigaciones, nos hemos deparado con la falta de materiales teóricos y didácticos - para profesores y alumnos - que traten de la enseñanza de PLAc bajo la perspectiva de la reterritorialización y producción de agencia. ¿Cómo elaborar una enseñanza acogedora, de hecho, sin que se reproduzca modelos que excluyen, que separan el alumno inmigrante del(de la) profesor(a) brasileño(a)? ¿El PLAc se configura como enseñanza de lengua adictiva o diminutiva mientras que es la lengua de un nuevo espacio de vivencias para sujetos migrantes? Teniendo en cuenta el estado del arte de las investigaciones y aserciones propuestas hasta este momento sobre el acogimiento en lengua portuguesa, buscamos reflexionar de qué manera el PLAc incide sobre las políticas para inmigrantes refugiados en Brasil, además de discutir las nomenclaturas inmigrante y refugiado.

PALABRAS CLAVE: Portugués como Lengua de Acogimiento. Dislocados forzados. Políticas lingüísticas. Políticas sociales.

ABSTRACT: In this paper, we consider the teaching of Portuguese as a Welcoming Language in Brazil - which is represented by the initial "PLAc" - as a way of producing agency for the conquest of rights to forced immigrants. Our motivation to undertake this discussion is given by the fact that the teaching of PLAc is recently debated in the public and academic spheres, consequently, it is necessary to start new researches to develop this linguistic field, taking into account the discussion about linguistic policies that overlap the horizontalities and verticalities. Moreover, throughout our research, we are faced with the lack of theoretical and didactic materials - for teachers and students - that deal with PLAC teaching from the perspective of reterritorialization and agentivity. How to elaborate welcoming teaching avoiding the reproduction of excluding models that separate the immigrant student from the Brazilian teacher? Does the PLAc constitute a diminutive or additive language teaching while it is the language of new living space for migrant people? In view of the state of the art of the researches and assertions so far proposed, we reflect in what way the PLAc focuses on the policies for refugee immigrants in Brazil, besides discussing the nomenclatures "immigrant" and "refugee".

KEYWORDS: Portuguese as a Welcoming Language. Forced immigrants. Language policies. Social policies.

\section{Introdução}

O processo migratório é uma questão global e histórica, sendo caracterizado por razões diversas, como colonização, importação de mão-de-obra, migração pós-guerra, entre outras situações que motivaram o deslocamento espaço-cultural de sujeitos no transcorrer da história. A formação do Brasil se alinha à dinâmica migratória e suas diversas motivações: dado o começo das grandes navegações portuguesas, o crime da comercialização de escravos africanos, as migrações italianas, alemãs, espanholas, japonesas, polonesas, entre outras, esses povos e os nativos indígenas passaram a compor, desde então, a população brasileira. Tamanha dimensão 
geográfica passou a se constituir também como uma enorme dimensão cultural e, consequentemente, linguística, sendo este o objeto central que dá o tom das discussões aqui empreendidas. Ainda que os recorrentes e diversos fluxos migratórios façam parte da história e do presente do Brasil, caracterizando as regiões do território nacional, comunidades de fala e práticas culturais, o atual fluxo migratório, o qual optamos por chamar neste escrito de deslocados forçados (AYDOS, 2010; ROSSA MENEZES, 2018), ainda carece de políticas sociais e linguísticas que de fato promovam o acolhimento necessário para que possa participar socialmente do Estado brasileiro.

Apesar das mudanças políticas, legislativas e econômicas que marcam o rumo sociopolítico do Brasil nos últimos anos, a chegada dos novos imigrantes - quais sejam, haitianos, senegaleses, ganenses e venezuelanos, que compõem, de acordo com Cavalcanti (2016), o maior número de imigrantes inseridos no mercado de trabalho formal - se deu de forma muito rápida, o que acarretou mudanças no quadro social, demandando políticas públicas para o acolhimento no país. Embora as razões para migrar de cada uma dessas nações mencionadas não sejam as mesmas, as barreiras encontradas no país recebedor por vezes são semelhantes, como a língua, inserção no mercado de trabalho e adaptação sociocultural. Nos debruçaremos sobre algumas delas ao longo do texto, com foco no aspecto linguístico.

Partindo de uma discussão sobre o termo refugiado (AYDOS, 2010; ROSSA; MENEZES, 2018), dedicamo-nos especificamente à discussão sobre o ensino de português para imigrantes em situação de refúgio no Brasil, cunhado como Português como Língua de Acolhimento (PLAc), ainda que sobre o termo acolhimento caibam reflexões $\mathrm{e}$ questionamentos (LOPEZ, 2016; ANUNCIAÇÃO, 2017). Para compreender as implicações do uso do termo e sua historicidade, discorreremos acerca do que entendemos por Português como Língua Adicional (SCHLATTER; GARCEZ, 2012) e PLAc, evidenciando o que pressupõe essa nova forma de ensinar, seus limites e contornos, tendo em vista que um ensino de língua profícuo é desenvolvido quando se tem conhecimento da(s) necessidade(s) do(s) aluno(s), bem como de sua(s) cultura(s) e particularidades que devem ser consideradas e respeitadas nos processos de ensino-aprendizagem. Para tanto, nos questionamos e buscamos responder, no que tange a políticas linguísticas e sociais: quais sãos as implicações de um ensino de língua acolhedor? Como é possível promover acolhimento dessa forma?

A fim de responder a tais questionamentos, nosso trabalho se propõe a explorar o conceito PLAc, no que diz respeito ao termo acolhimento e à produção de agenciamentos através do processo de ensino-aprendizagem de português à deslocados forçados. Também discutiremos o que entendemos por agenciamentos (BIZON, 2013; LOPEZ, 2016) e de que 
forma eles podem ser promovidos dentro desse viés. Nos debruçamos sobre esse debate, com a intenção de pensar o que é preciso fazer e o que já é feito para que o PLAc seja acolhedor sem segregar. Paralelamente à problemática do ensino acolhedor, abordamos os conceitos de educação do entorno (MAHER, 2007), agentividade (CANAGARAJAH, 2004), desterritorialização/reterritorialização para além do espaço geográfico (DELEUZE; GUATARRI, 1995; BIZON, 2013), além de lançarmos questionamentos sobre ações de ensino que se organizam nas esferas horizontais e verticais (SANTOS, 1996; 2001). Tais autores e as temáticas mobilizadas sustentam nossa discussão sobre políticas linguísticas elaboradas para imigrantes refugiados, perpassando diversas áreas do conhecimento, como é de costume dentro da linha de pesquisa em Linguística Aplicada a qual nos filiamos, notadamente transdisciplinar (SIGNORINI, 1998; MOITA LOPES, 2006).

\section{Migrantes e as diversas adjetivações que podem receber}

Entendemos que nomenclaturas são imbuídas de ideologias, por isso, termos como imigrante e refugiado não são intercambiáveis. Devido a este artigo se ocupar do ensino de língua e por se filiar a uma Linguística Aplicada transdisciplinar - a qual, em linhas gerais, valese de conhecimentos construídos em outros domínios de conhecimento além da linguagem - é relevante tratar sobre migração e refúgio em aspecto mais amplo, uma vez que é nesta área que se localiza o ensino de PLAc. As autoras Rossa e Menezes (2018) corroboram com o nosso entendimento sobre a importância de que a área da linguagem se ocupe da discussão sobre migração e refúgio e afirmam que:

\footnotetext{
(...) a reflexão sobre o uso e reprodução das categorias migratórias na prática de pesquisa, é um compromisso a ser assumido por todos os pesquisadores do tema de deslocamento humano desde o sul global, por entender que nossas práticas influenciam a forma como os indivíduos serão vistos e recebidos pelos Estados e instituições; Mais do que classificar e rotular, devemos, antes, tentar compreender a captar as realidades de pessoas migrantes no Brasil, reconhecendo os limites das categorias existentes sem esquecer de problematizá-las (ROSSA; MENEZES, 2018, p. 398, grifos nossos)
}

Dedicamos esta seção de abertura do artigo às tipologias migratórias, a fim de assumirmos o compromisso de reconhecer os limites de categorias como "migrantes", "estrangeiros" e "refugiados", problematizando-as. O entendimento de tais nomenclaturas a partir de saberes da área jurídica evita que se recaia ao uso positivista de termos que não podem ser reduzidos a fenômenos evidentes, objetivos e neutros. É complexo categorizar os 
deslocamentos pelo mundo na atualidade, principalmente em virtude da dificuldade de pautar o status de um migrante somente nos elementos voluntariedade e compulsoriedade, visto que essas motivações não são facilmente detectáveis e seus contornos são fluídos. Como exemplo de dificuldade de se compreender os status como fenômeno objetivo, mobilizamos o caso dos refugiados angolanos. Segundo Rossa e Menezes (2018, p. 385), esses eram reconhecidos de maneiras distintas por influência da classe social, "podendo pessoas com situações idênticas serem classificadas como refugiados, deslocados, retornados, repatriados e expatriados". Nesse exemplo, evidencia-se a influência de elementos políticos e econômicos na categorização dos sujeitos, indicando a complexidade das tipologias migratórias e as diversas variáveis que condicionam o reconhecimento daqueles que migram.

Ademais, o status legal concedido aos indivíduos que compõem os fluxos migratórios exige atenção, visto que os direitos desses sujeitos são legalmente garantidos de acordo com a categoria a qual pertencem, havendo diferença nas proteções que o estado garante a um refugiado e a um portador de visto humanitário, por exemplo. Esses rótulos também servem para gerar estatísticas capazes de forjar um cenário positivo ou não sobre os sujeitos. $\mathrm{Na}$ atualidade, é comum depararmo-nos com a afirmação de que vivemos uma crise humanitária de refugiados, e à categoria "refugiado" associam-se algumas nacionalidades e a classes sociais específicas, gerando uma resistência coletiva a grupos específicos que passam a ser malquistos por virem em grande número, capaz de desestabilizar um estado-nação. Contudo, os números bem como nomenclaturas são manipuláveis e não expressam necessariamente a realidade: os países do norte global produzem estrangeiros, já os do sul global, produzem imigrantes e refugiados.

Outro efeito da criação de nomenclaturas é a homogeneização e redução de uma situação complexa e heterogênea como é a migração na contemporaneidade, ao encaixar os novos migrantes à categoria dicotômica migrante/refugiado, considerando aqueles como deslocados voluntários e esses como forçados, sem levar em conta as diferentes situações que atravessam cada um dos termos. Dessa forma, "nossa interpretação é de que a migração não ocorre sempre como um ato voluntário, e que dentre outros processos que podem caracterizála, podemos sim incluir a violência como um fator migratório" (VAINER, 1996 apud AYDOS, 2010, p. 53). Assim, é possível que aqueles reconhecidos legalmente como migrantes econômicos não tenham deixado seus países voluntariamente, mas sim devido a óbices relacionados aos direitos humanos, compartilhando de motivações migratórias semelhantes às dos indivíduos reconhecidos como refugiados. 
Em virtude das complexidades existentes nas nomenclaturas e as suas implicações sociais e jurídicas, optamos por nos alinhar ao uso do conceito analítico de migração forçada, denominando os sujeitos participantes desse processo como deslocados forçados. O conceito de migração forçada engloba conceitos jurídicos como o de refugiado, deslocados internacionais, refugiados ambientais e solicitantes de refúgio (AYDOS, 2010; ROSSA; MENEZES, 2018). Outro termo que merece atenção, o qual também aparece em publicações sobre o ensino de PLAc, é o de "migração por sobrevivência", proposto por Betts (2010); justifica-se que tal termo não reforça a dicotomia migração forçada versus migração voluntária, uma vez que, "quando sair do país é a única opção para garantir a sobrevivência, é irrelevante classificar as causas dessas privações em econômicas ou provenientes de conflitos" (BETTS, 2010 apud ROSSA; MENEZES, 2018, p. 392). Apesar de esse ser um conceito aparentemente benéfico, Rossa e Menezes (2018) pontuam que a noção de sobrevivência proposta pela categoria reforça o historicamente construído discurso de insuficiência dos países do sul global, o que pode servir como argumento para legitimar intervenções militares internacionais vindas das grandes potências mundiais, com interesses escusos.

Para concluirmos essa breve discussão sobre a implicação dos termos que utilizamos em nossas pesquisas ao nos referirmos aos sujeitos provenientes dos novos fluxos migratórios, indicamos como leitura complementar aos que desejam se aprofundar no assunto a dissertação de Aydos (2010) e o artigo de Rossa e Menezes (2018); nesses textos, pode-se encontrar discussões relevantes sobre migrações, como o reconhecimento de asilo humanitário para haitianos, a complexa situação dos solicitantes de refúgios vindos de Angola, bem como maiores explicações sobre a defesa dos limites da categoria jurídica refugiado a fim de que não haja perda nas políticas específicas para esses. A seguir, discutimos o contexto de ensino de português a deslocados forçados, Português como Língua de Acolhimento.

\section{Português como Língua de Acolhimento: o que ensinar? Como ensinar? De que forma a língua acolhe?}

A guisa de explicação, nesse trabalho compreendemos que o PLAc se configura como uma subárea do PLA - Português como Língua Adicional, marcada por tal nomenclatura a fim de construir historicidade para o termo, agrupando pesquisas que se dedicam ao ensino de português como língua não materna a deslocados forçados. Desse modo, nos cabe, primeiramente, explicar o que entendemos por Português como Língua Adicional e Português 
como Língua de Acolhimento, bem como nossa identificação teórica e ideológica com o uso dessas definições.

De acordo com Schlatter e Garcez (2012), língua adicional diz respeito ao ensino de outra língua no repertório do aluno que, diferentemente do uso do termo língua estrangeira (LE), remete a um ensino aditivo, que se incorpora à vida do aluno para além do ensino de uma língua, que lhe possa ser útil para a comunicação nas mais diferentes esferas da comunicação humana (BAKHTIN, 2016) e para o uso e ação social da linguagem (CLARK, 2000). Optamos por PLA (Português como Língua Adicional) e não por PLE (Português como Língua Estrangeira) porque consideramos, além das razões supracitadas, que língua estrangeira remete a algo estranho, alheio, distante, conceitos que não consideramos positivos no ensino de língua.

Para além das considerações feitas a respeito do ensino de PLA, compreendemos que o ensino de PLAc, como subárea do Português como Língua Adicional, cobra certas especificidades, tendo em vista que o alunado de PLAc, oriundo dos processos de migração forçada, busca, através do idioma, algumas outras formas de participação na sociedade que não são as mesmas que as buscadas por imigrantes turistas ou pessoas que precisam aprender português por outras razões. Em outras palavras, as razões pelas quais o alunado de PLAc busca aprender português são, basicamente, sobreviver em uma sociedade que não o considera, até o presente momento, que coexiste com outras línguas além do português, que ainda não está preparada para receber falantes de outros idiomas e a busca da inserção no mercado de trabalho, na escola, fazer parte das atividades sociais do país. Face à relação entre o aprendizado da língua majoritária do Brasil e a migração, faz-se necessário abordar a questão das políticas linguísticas.

\section{Ensino de português a deslocados forçados: Políticas Linguísticas}

Embora o Brasil seja um país plurilíngue, que tem como língua oficial o português, a Língua Brasileira de Sinais (Libras), que conta com comunidades indígenas falantes de línguas indígenas, comunidades de imigrantes falantes de italiano, alemão, japonês, polonês e idiomas dialetais, não há, hoje, políticas linguísticas que promovam o acolhimento dos novos imigrantes em outras línguas, tampouco políticas linguísticas que valorizem os outros idiomas falados no Brasil - que não sejam português e Libras. Tais línguas e os chamados idiomas dialetais são considerados minoritários, uma forma eufêmica de diminuir e barrar construções linguísticas e culturais que possam surgir dentro desses grupos. Da mesma forma que essas línguas são 
tratadas, as línguas e a cultura dos imigrantes também passam por tentativas de apagamento, ao passo que se promove o acolhimento em português. De acordo com Maher:

A imensa maioria dos brasileiros, conforme afirmou Marilda Cavalcanti, em 1999, não (re)conhece a extensão da pluralidade linguística de seu país. Porque acredita que o Brasil é, ou deveria ser, linguisticamente uniforme, essa maioria olha para o nosso atlas linguístico e não vê, ou faz que não vê, as mais de 180 línguas indígenas e as cerca de 30 línguas imigrantes faladas cotidianamente por cidadãos brasileiros natos. Tampouco enxerga, ou vê com bons olhos, o uso das línguas de sinais brasileiras e os nichos religiosos (terreiros de candomblé) e comunidades quilombolas, onde ainda se fazem presentes, em cânticos e orações, línguas africanas (MAHER, 2007, p. 226, grifos nossos)

Em seu texto A Educação do Entorno, a autora discorre sobre o conceito de língua e cultura, de modo que esclarece que ambas estão atreladas e fazem parte da constituição dos sujeitos, estabelecendo-se de forma dialógica. A autora considera que, ao passo que ocorrem mudanças nas organizações sociais e nas relações humanas, a cultura não é e não pode ser um conceito engessado, tampouco estereotipado, pertencente a determinado grupo dominante (MAHER, 2007). Portanto, considera que a educação do entorno deve abarcar a cultura de todos aqueles que constituem o espaço social, desde grupos hegemônicos até de grupos minoritarizados, abrindo espaços para que se possa manifestar e problematizar em sala de aula as diversas culturas coexistentes, por mais divergentes que sejam. Entendemos que língua é também cultura e que ambas fazem parte de determinados lugares, momentos, grupos e é através delas que os sujeitos inseridos na linguagem performam suas identidades. Pensando dessa forma, nos questionamos: de que forma o ensino de PLAc acolhe também outras culturas?

Defendemos o entendimento de que o termo acolhimento é um eufemismo, uma vez que só acolhe imigrantes em um idioma que não é dominado por eles e que não há, por parte do governo, políticas linguísticas que promovam esse acolhimento em língua portuguesa. Conforme Grosso (2010, p. 74)

o conceito de língua de acolhimento aproxima-se da definição dos conceitos de língua estrangeira e língua segunda ${ }^{3}$, embora se distinga de ambos. É um conceito que geralmente está ligado ao contexto de acolhimento, expressão que se associa ao contexto migratório, mas que, sendo geralmente um público adulto, aprende o português não como língua veicular de outras disciplinas, mas por diferentes necessidades contextuais, ligadas muitas vezes à resolução de questões de sobrevivência urgentes, em que a língua de acolhimento tem de ser o elo de interação afetivo (bidirecional) como primeira forma de integração (na imersão linguística) para uma plena cidadania democrática.

${ }^{3}$ E língua adicional. 
Compreendemos que um país plurilíngue, onde políticas linguísticas para idiomas minoritários são precárias, não está preparado para atender um novo público falante de diferentes idiomas. No entanto, também não há, por parte do estado, incentivo para o ensino de português acessível a esse público. Ou seja, o país está aberto para receber imigrantes, porém, eles devem falar português e devem ser individualmente responsáveis pelo aprendizado. Quando o Estado não se responsabiliza por determinadas causas, muitas vezes, cabe à sociedade civil realizar o trabalho (MARQUES, 2018).

Nesse segmento, tem-se a criação de ONGs e espaços gratuitos de ensino de PLAc, coordenados e ministrados por voluntários, onde é comum que os professores de PLAc não sejam formados, tampouco sejam estudantes de Letras, o que, por um lado se vê como uma atitude muito grandiosa, pelo fato de dedicarem-se a um trabalho em que não têm tanto conhecimento, em prol de uma causa muito necessária. Por outro lado, esse ato de lecionar sem formação pode ser problemático por questões das concepções de linguagem que embasam o trabalho, o que reflete na prática docente; Amado (2013) considera que

\begin{abstract}
Ainda que o papel de voluntários não docentes ministrando português para os refugiados seja essencial em caráter emergencial, é inconcebível que um país que possui mais de 400 cursos de Letras e que forma cerca de 31000 professores por ano (PAIVA, 2005) não possa criar um programa que contrate professores, mesmo que sem formação inicial em PLE visto ser este um outro problema de currículo nos cursos de Letras, para o ensino de português como língua de acolhimento para imigrantes trabalhadores transplantados e refugiados (AMADO, 2013, s/p)
\end{abstract}

Levando em conta a importância das políticas linguísticas na regulamentação e promoção do PLAc, aprofundamos este debate a partir da abordagem proposta por Ricento e Hornberger (1996). Os autores utilizam a metáfora da cebola para promover a compreensão das políticas linguísticas e de seu funcionamento, em que cada camada do vegetal simboliza uma força de ação responsável para a constituição de políticas de linguagem. As camadas externas representam as esferas políticas e legislativas que institucionalizam, através de decretos, leis e regulamentações, questões referentes à promoção, ao veto, ao reconhecimento, ao ensino de línguas; o centro da cebola representa os docentes que produzem política linguística em seu cotidiano de ação, de maneira deliberada ou não, visto que todos os atos são atravessados por concepções de linguagem que reproduzem políticas institucionalizadas ou que se opõem a elas. Apesar dessas camadas interdependerem umas das outras, e a despeito das legislações terem poder sobre as "camadas internas", admite-se o poder de ação do professor em sua prática diária em sala de aula, ao fazer política linguística na horizontalidade. 
Acrescentamos ao termo "horizontalidade" os conceitos de verticalidade e horizontalidade propostos por Santos $(1996 ; 2001)$. Para o geógrafo, verticalidades são "pontos no espaço que, separados uns dos outros, asseguram o funcionamento global da sociedade e da economia" (SANTOS, 1996, p. 194), já as horizontalidades são pontos que se agregam em continuidade. Esses conceitos que perpassam os espaços geográficos e sociopolíticos dizem respeito às políticas e institucionalização de ações e legislações em geral, mas também linguísticas. A tendência atual de união vertical diz respeito à globalização, que apregoa a homogeneidade de corpos e lugares, baseada numa administração hierarquizante e reprodutora de regras e normas externas que têm "um efeito desintegrador das solidariedades locais então vigentes, com a perda correlativa da capacidade de gestão da vida local” (SANTOS, 1996, p. 193).

Ao transpormos os conceitos de verticalidade e horizontalidade às questões linguísticas, podemos pensar as regulamentações e legislações como ações que se dão nas verticalidades e as ações locais/ordinárias como horizontais ao promoverem a reintegração das solidariedades e a gestão de vida local. Ou seja, as ações linguísticas profícuas aos deslocados forçados que estão no Brasil devem levar em conta as reivindicações daqueles que compartilham os espaços banais com esses novos imigrantes, sejam professores de PLAc, ONGs, instituições de ensino que já promovem o acolhimento. Tal como a metáfora da cebola, em que as camadas se sobrepõem e interferem umas nas outras, as verticalidades e as horizontalidades coexistem e estão inter-relacionadas, pois é preciso o reconhecimento, através de leis (verticais), que garantam o acolhimento já praticado pelas horizontalidades. Dessa forma, defendemos uma política de atravessamentos, como proposto por Bizon e Camargo (2018). Após discorrermos sobre a precariedade de políticas linguísticas para grupos minoritários, especialmente deslocados forçados, debatemos conceitos caros à discussão do ensino a grupos minoritários.

\section{Agenciamento, agentividade e territorialização, na construção do ensino de PLAc}

Ana Paula Lopez (2016), discorre, em seu trabalho, acerca de certos entendimentos por parte de professores, alunos e coordenados de um centro de ensino de PLAc. A autora trata das concepções estigmatizadas sobre os deslocados forçados, sobre a condição do ensino de PLAc também estigmatizada por professores, coordenadores e inclusive os próprios alunos do curso e, a partir de sua análise, sugere que o ensino se volte à elaboração de agenciamentos para a promoção de políticas sociais e econômicas. 
Nossa concepção de agenciamentos é baseada no que sustentam Lopez (2016) e Bizon (2013), considerando atos e ações que buscam dar voz, politizar, apropriar-se de espaços e territórios. Entendemos, a partir disso, territorialização como um processo não geográfico (DELEUZE; GUATARRI, 1995; BIZON, 2013) posto que território não se trata de apenas espaços físicos, mas de lugares de pertença, "sinônimo de apropriação" e, conforme Bizon (2013), apropriar-se de algo pressupõe uma agência. Entendemos, pois, territorialização e agenciamentos, dentro da perspectiva do ensino de PLAc, como ações para promover maior sensação de pertencimento dos deslocados forçados que participam da sociedade que só os "acolhe" em português. Para mais, não é apenas conhecendo um idioma que se consegue ser cidadão e atuar na sociedade, reivindicar, resistir às redes de poder em que estamos inseridos. É preciso aprender a ser crítico. É preciso ter voz através e além da língua. É preciso abrir espaços, geográficos ou não, e pertencer a eles.

Como exemplo, Anunciação (2017) relata, em seu trabalho, um caso onde alunos imigrantes refugiados haitianos puderam expressar, através de um vídeo, sua reprovação a uma matéria televisiva veiculada em rede nacional. Os alunos se sentiram incomodados com o estigma e a forma de abordagem, considerando preconceituosa a forma com que o Haiti fora retratado. A partir disso, se organizaram, junto com a professora, para escrever em um roteiro o que diriam no vídeo. O vídeo é protagonizado pelos alunos e a mensagem consegue chegar aos interlocutores, o apresentador do programa e o público brasileiro. Consideramos que essa é uma forma de uso de PLAc para promoção de agenciamentos, uma vez que a sala de aula foi espaço para reflexão e promoção de ações - que não precisam ser, necessariamente verbais e, menos ainda, em português - que corroboram com a sensação de pertença. Em consonância ao conceito de agenciamento, está o conceito de agentividade, nos termos propostos por Canagarajah (2004). Para o autor, a agentividade e a resistência, capazes de empoderar alunos pertencentes a grupos minoritários, permitem uma adaptação mais qualificada dos sujeitos, portanto, é importante promover em sala de aula momentos que permitam que os alunos exerçam sua agentividade, negociando suas identidades e consequentemente trazendo benefícios para o desenvolvimento da aprendizagem.

Diante das considerações acerca do ensino de PLAc feitas até agora, ainda cabe discutir a diferença a respeito de questões de aprendizagem em língua, que se devem levar em conta para a elaboração das aulas e dos materiais didáticos. Elencamos algumas delas:

- A respeito do alunado de PLAc:

- Horários limitados devido à carga horária de trabalho do alunado; 
- Público heterogêneo em relação a níveis de proficiência: o que pode ser positivo para algumas atividades em grupo, mas talvez enfadonho para os alunos mais proficientes, podendo acarretar em desistência;

- Alunos que sabem falar mais de um idioma têm mais facilidade para aprender outros idiomas, devido a relações feitas anteriormente durante a aprendizagem da segunda ou terceira língua;

- Alunos que não são alfabetizados em nenhuma língua: como integrar esses alunos em uma aula de língua? Que tipo de prática de letramento pode ser realizada para incluir esse aluno em aula?

○ Cultura, concepção de cultura, hábitos e práticas diferentes entre si e diferentes dos professores. Como promover um ensino que não corrobore com o apagamento dessa cultura, um ensino não hegemônico, que seja democrático e crie espaços para a promoção de uma aprendizagem que contemple língua e cultura?

○ O que os alunos querem aprender? O que eles precisam aprender? Por que eles querem aprender? Essas são perguntas que podem ser feitas em todos os grupos de alunos, para que se possa realizar um ensino que de fato contemple as necessidades do aluno e que tenha maiores possibilidades de engajamento;

- Quais são as motivações dos alunos para estarem em uma aula de PLAc? Como eles perceberam que precisam e para que precisam aprender português? Quais são os lugares que eles transitam e quais eles gostariam de transitar?

- Aos professores de PLAc:

- Conhecer as necessidades do grupo para a elaboração das aulas e dos materiais didáticos;

- Conhecer as especificidades do ensino de PLA e do ensino de PLAc;

- Valorizar a cultura e a vivencia dos alunos;

- Desenvolver um ensino que articule a promoção de agenciamentos e processos de territorialização;

- Aos pesquisadores e produtores de conhecimento acerca do tema:

- Refletir acerca do termo acolhimento;

- Elaborar políticas linguísticas para o ensino de PLAc e formação de professores para o ensino de PLAc; 
- Produzir reflexões e teorias a respeito do tema, e orientar a produção de materiais didáticos;

- Abrir espaços e oportunidades para a discussão sobre o PLAc nas universidades e nas escolas, dando voz a quem quer conhecer e quem já conhece, a fim de criar comunidades colaborativas maiores e divulgar as asserções acerca do tema.

Com isso, consideramos que deve haver mais reflexões sobre o tema, a fim de promover um ensino que não reproduza os processos de segregação que se configuram na história dos povos e línguas minoritárias de nosso país.

\title{
PLAc, imigrantes refugiados e a vida no Brasil
}

\author{
de repente todos somos imigrantes \\ trocando uma casa pela outra \\ primeiro trocamos o ventre pelo ar \\ depois o subúrbio pela cidade imunda \\ em busca de uma vida melhor \\ mas alguns de nós abandonam sua terra por completo
} (Rupi Kaur)

Podemos analisar a relação dos imigrantes refugiados com a língua como uma forma de concessão à cidadania. Não nos referimos somente à cidadania legal, mas como sinônimo de pertença. O Estatuto do Refugiado (BRASIL, 1951) confere:

Art. $1^{\circ}$ Será reconhecido como refugiado todo indivíduo que:

I - devido a fundados temores de perseguição por motivos de raça, religião, nacionalidade, grupo social ou opiniões políticas encontre-se fora de seu país de nacionalidade e não possa ou não queira acolher-se à proteção de tal país; II - não tendo nacionalidade e estando fora do país onde antes teve sua residência habitual, não possa ou não queira regressar a ele, em função das circunstâncias descritas no inciso anterior;

III - devido a grave e generalizada violação de direitos humanos, é obrigado a deixar seu país de nacionalidade para buscar refúgio em outro país

Entretanto, a garantia do direito, em outras palavras, do papel, não confere ao indivíduo a liberdade para participar de todas as atividades que quiser na sociedade brasileira. Pode-se dizer que também não é possível a todos os brasileiros viver e transitar em determinados lugares físicos e idealizados por razões consideradas normas, ou regras, dentro das redes de micropoderes. Se olha para a questão do refúgio da mesma forma que se olha para as políticas de inclusão, concedendo espaços a minorias que, até então não pertenciam a esses espaços. 
Sob a perspectiva de Michel Foucault, o poder não deve ser visto como proibição, ou punição - isso é abuso de poder - e deve ser analisado sob uma perspectiva ascendente, captando as relações de poder que existem em todas as estruturas, antes do poder do Estado. De acordo com Foucault:

Trata-se [...] de captar o poder em suas extremidades, lá onde ele se torna capilar; captar o poder nas suas formas e instituições mais regionais e locais, principalmente no ponto em que, ultrapassando as regras de direito que o organizam e o delimitam, ele se prolonga, penetra em instituições, corporificase em técnicas e se mune de instrumentos de intervenção material, eventualmente violentos (FOUCAULT, 1996, p. 182).

As relações entre imigrantes refugiados e brasileiros se identificam nessa definição. Há também relações de poder, nas quais podemos observar, em muitas situações o olhar voltado aos refugiados e às minorias com ódio ou pena, conforme relata Lopez (2016). Muito embora por direito eles possam pertencer e se estabelecer na sociedade, há espaços, geográficos ou não, que não estão abertos para eles.

A condição de refugiado outorga determinadas liberdades e privações à vida em sociedade. $\mathrm{O}$ ensino de PLAc, nesse sentido, deve promover possibilidades de agenciamentos para que essas liberdades sejam cada vez mais possíveis e abertas. Ainda que as redes e os micropoderes estejam fortes, quase consolidadas, assolando muitos espaços dos quais todos fazemos parte, "onde há poder, há possibilidade de resistência" (DANNER, 2010). Conforme Foucault (apud GALLO, 2017, p. 90):

Sem dúvida, o objetivo principal, hoje, não é descobrir, mas recusar o que nós somos. [...] Poder-se-ia dizer, para concluir, que o problema, ao mesmo tempo, político, ético, social e filosófico que se apresenta a nós, hoje, não é tentar liberar o indivíduo do Estado e de suas instituições, mas de nos livrarmos, nós, do Estado e do tipo de individualização que ele pretende.

Consideramos que os agenciamentos, agentividade, ou a resistência, deve conversar com processos de desterritorialização/territorialização para além do espaço geográfico. O que significa a construção de agenciamentos e de resistência a fim de participar de forma ativa na sociedade, relacionar-se com a cultura brasileira e ter espaço para divulgar culturas outras, ter mais possibilidades de inserção no mercado de trabalho e em práticas cotidianas. O documento de refugiado confere possibilidades que o status de refugiado, muitas vezes, não confere. $\mathrm{O}$ preconceito racial, de gênero, social e religioso assola muitas das relações. Por essa razão, consideramos que uma forma de resistir e promover agenciamentos é fazer com que nossos 
alunos de PLAc aprendam português não apenas para servir ao modelo neoliberal que estamos inseridos, mas para reivindicar junto conosco uma sociedade mais justa e menos segregada.

São tempos de resistência, sabemos. Valendo-nos das palavras de Foucault (apud GALLO, 91-92):

[...] considerando que não haja sociedade sem relações de poder, o agonismo entre poder e liberdade é uma tarefa incessante, uma tarefa política inerente à existência social, à existência de qualquer um na sociedade, o que vale dizer: a luta pela liberdade, a luta pelo desgoverno, a resistência ao aprisionamento das possibilidades de ação pertence ao homem comum, é sua tarefa política. Insistir em existir, existir enquanto múltiplas possibilidades [...], insistir em existir de novo e de: re-existir.

Produzir agenciamentos, resistir, insistir e re-existir. Tarefas que nos cabem tanto como cidadãos da sociedade brasileira, cada vez mais consolidada em relações de poder - e de abuso de poder - que devem passar de brasileiros para imigrantes, professores para alunos, compartilhando redes colaborativas de resistência, de aprendizagem, de trocas e novas formas de subjetivação para a construção de espaços mais justos e plurais.

\section{Considerações finais}

Neste artigo, buscamos responder, no que tange a políticas linguísticas e sociais: quais as implicações de um ensino de língua acolhedor? Como é possível promover acolhimento dessa forma? A partir da discussão fomentada, unimos nossa voz aos trabalhos que discutem ações para o acolhimento interculturais e politicamente engajadas de imigrantes compreendidos como deslocados forçados, quais tenham o status de refugiados, imigrantes com visto permanente, imigrantes com visto humanitário, solicitantes de refúgio, entre outros. Assumimos que para produzir diálogos produtivos, como linguistas aplicados, não podemos nos encerrar na área da linguagem.

Salientamos a importância de que as aulas de PLAc sejam abertas para que os alunos construam sua agentividade, já que, em muitos casos, este é o único espaço comum para a construção da identidade de imigrante deslocado forçado como grupo resistente no Brasil, visto que nem sempre há organizações secundárias para que esses debates ocorram, como associações de imigrantes. Por isso, a aula de PLAc ultrapassa o espaço de ensino de língua como cultura e se configura como um espaço de construção de agentividade. Dessa forma, a sala de aula como um espaço democrático e constituído por imigrantes é reflexo das mudanças 
sociais que estão ocorrendo e paulatinamente desconstruindo a ultrapassada concepção de Estado nação unicultural e monolíngue.

AGRADECIMENTOS: À CAPES e CNPq, pelas bolsas concedidas.

\section{REFERÊNCIAS}

AMADO, R. O ensino de português como língua de acolhimento para refugiados. Revista da Sociedade Internacional Português Língua Estrangeira (SIPLE). 7ed., ano 4, n. 2, 2013.

ANUNCIAÇÃO, R. F. M. Somos mais que isso: práticas de (re)existência de migrantes e refugiados frente à despossessão e ao não reconhecimento. Dissertação de mestrado. Universidade Estadual de Campinas, 2017.

AYDOS, M. R. Migração Forçada: Uma abordagem conceitual a partir da imigração de angolanos para os estados de São Paulo e Rio de Janeiro, Brasil (1970-2006). Dissertação de Mestrado. Campinas, SP, 2010.

BAKHTIN, M. Os gêneros do discurso. São Paulo, SP: Editora 34 Ltda, 2016.

BETTS, A. Survival Migration: A New Protection Framework. Global Governance: A Review of Multilateralism and International Organizations. v. 16, n. 3, p. 361-382, JulySeptember 2010.

BIZON, A. C. C. Narrando o exame Celpe-Bras e o convênio PEC-G: a construção de territorialidades em tempos de internacionalização. Tese de Doutorado. Campinas, SP, 2013.

BIZON, A. C. C; CAMARGO, H. R. E. Acolhimento e ensino da língua portuguesa à população oriunda de migração de crise no município de São Paulo: por uma política do atravessamento entre verticalidades e horizontalidades. In: BAENINGER; BOGUS; BERTINO MOREIRA; VEDOVATO; FERNANDES; SOUZA; BALTAR; PERES; WALDMAN; MAGALHÃES. (Org.). Migrações Sul-Sul. 2ed. v. 1. Campinas, SP, 2018.

BRASIL. Estatuto do Refugiado, 1951.

CANAGARAJAH, A. S. Subversive identities, pedagogical safe houses, and critical learning. In: NORTON, B.; TOOHEY, K. (Orgs.). Critical pedagogies and language learning. Cambridge: Cambridge University Press. Cap. 7, p. 116-137, 2004.

CAVALCANTI, L. Novos fluxos migratórios: haitianos, senegaleses, e ganeenses no mercado de trabalho brasileiro. In: GIEDEL, J. A. P.; GODOY, G. G. (Org.). Refúgio e hospitalidade. Curitiba: Kairós Edições, 2016.

CLARK, H. H. O uso da linguagem. Cadernos de Tradução. Porto Alegre: UFRGS, $n^{\circ}$ 9, p. 49-71. jan-mar. 2000.

COLL, C. Psicologia e currículo: uma aproximação psicopedagógica à elaboração do currículo escolar. Tradução Cláudia Schilling. São Paulo: Ática, 1996. 
DELEUZE, G.; GUATARRI, F. Mil platôs: postulados da linguística. Rio de Janeiro: Editora 34, 1997.

DENNER, F. O Sentido da Biopolítica em Michel Foucault. Revista Estudos Filosóficos, $\mathrm{n}^{\circ}$ 4, p. 143-157, 2010.

FOUCAULT, M. Microfísica do Poder. 12ª Ed. Rio de Janeiro: Graal, 1996.

GROSSO, M.J.R. Língua de acolhimento, língua de integração. Horizontes de Linguística Aplicada, v. 9, n.2, p.61-77, 2010.

GALLO, S. Biopolítica e subjetividade: resistência? Educar em Revista. n. 66, p. 77-94, out/dez. 2017.

LOPEZ, A. P. A. Subsídios para o planejamento de cursos de Português como Língua de Acolhimento para Imigrantes Deslocados Forçados no Brasil. Dissertação de mestrado. Universidade Federal de Minas Gerais, 2016.

MAHER, T. A educação do entorno para a interculturalidade e o plurilinguismo. In: KLEIMAN, Angela; CAVALCANTI, Marilda (Orgs.). Linguística Aplicada - suas faces e interfaces. p. 255-270. Campinas: Mercado de Letras, 2007.

MARQUES, A. A. M. Políticas linguísticas e ensino de português como língua de acolhimento para imigrantes no Brasil: Uma discussão a partir da oferta de cursos nas universidades federais. Dissertação de Mestrado. Universidade Federal do Rio Grande do Sul. Porto Alegre, RS, 2018.

MOITA LOPES, L. P. Uma Linguística Aplicada mestiça e ideológica. In: MOITA LOPES, L. P. (Org.). Por uma Linguística Aplicada indisciplinar. p. 13-44. São Paulo: Parábola Editorial, 2006.

RICENTO, T.; HORNBERGER, N. H. Unpeeling the onion: Language planning and policy and the ELT professional. p. 401- 427. TESOL Quarterly, 1996.

ROSSA, L. A.; MENEZES, M. A. Entre Migrações e Refúgio: migrações sul-sul no Brasil e as novas tipologias migratórias. In: BAENINGER; BOGUS; BERTINO MOREIRA; VEDOVATO; FERNANDES; SOUZA; BALTAR; PERES; WALDMAN; MAGALHÃES. (Org.). Migrações Sul-Sul. 2ed., v. 1, Campinas: 2018.

SANTOS, M. A Natureza do Espaço: Técnica e Tempo, Razão e Emoção. São Paulo: Editora da Universidade de São Paulo, 1996.

SANTOS, M. Por uma outra globalização: do pensamento único à consciência universal. Rio de Janeiro, RJ/ São Paulo, SP: Editora Record, 2001

SCHLATTER, M.; GARCEZ, P. Línguas Adicionais na escola: aprendizagens colaborativas em inglês. Erechim, RS: Edelbra, 2012. 
SIGNORINI, I. Do residual ao múltiplo e ao complexo: o objeto da pesquisa em Linguística Aplicada. In: SIGNORINI, I; CAVALCANTI, M (Orgs.). Lingüística aplicada e transdisciplinaridade. Campinas: Mercado de Letras, p. 99-110, 1998.

VAINER, C. B. Estado e migração no Brasil: da imigração à emigração. In: Patarra, N. L. (coord.). Emigração e imigração internacionais no Brasil Contemporâneo. São Paulo: FNUAP, 1995.

\section{Como citar este artigo}

BULEGON, Mariana; SOARES, Laura Fontana. Impactos sociais dos novos fluxos migratórios e políticas linguísticas no Brasil: o ensino de Português como Língua de Acolhimento (PLAc). Revista on line de Política e Gestão Educacional, Araraquara, v. 23, n. 3, p. 638-655, set./dez., 2019. E-ISSN:1519-9029. DOI:

Data de Submissão: 06/05/2019

Revisões Requeridas: 21/06/2019

Aceite em: 29/07/2019

Publicado em: 15/08/2019 